\title{
MODELLING KEY MARKET IMPACTS AND LAND ALLOCATION FOR BIOFUEL PRODUCTION AND FORESTRY
}

\author{
A. KOROBEINIKOV, P. READ, A. PARSHOTAM, AND J. LERMIT
}

Received 10 December 2004; Accepted 19 April 2005

It has been suggested that the large scale use of biofuel, that is, fuel derived from biological materials, especially in combination with reforestation of large areas, can lead to a low-cost reduction of atmospheric carbon dioxide levels. In this paper, a model of three markets: fuel, wood products, and land are considered with the aim of evaluating the impact of large scale biofuel production and forestry on these markets, and to estimate the cost of a policy aimed at the reduction of carbon dioxide in the atmosphere. It is shown that the costs are lower than had been previously expected.

Copyright (c) 2006 A. Korobeinikov et al. This is an open access article distributed under the Creative Commons Attribution License, which permits unrestricted use, distribution, and reproduction in any medium, provided the original work is properly cited.

\section{Introduction}

It has been suggested [8] that large scale biofuel production, especially in combination with sequestration forestry, can achieve a low cost reduction in greenhouse gas levels, in particular $\mathrm{CO}_{2}$, and hence lead to meeting the ultimate objective of the Kyoto Protocol to the UN framework convention on climate change (UNFCCC). (Here by the term "sequestration" we mean extraction of atmospheric carbon and storing it by growing trees.)

Biofuel (the fuel derived from biological materials) substitutes fossil fuels and thus, through fossil fuels not extracted, prevents release of underground fossil carbon. Biofuel is also a renewable fuel that provides chemically stored energy that can potentially substitute fossil fuel with minimal infrastructural change and may provide a backstop technology until other innovative technologies take a sufficient market role.

Forestry offers a large mitigation potential with modest costs, low risk and other benefits and is one of the few "no regrets" opportunities available in most countries all over the world [4]. The Kyoto Protocol's Article 3.3 recognises enhancing forest sinks as a mean of meeting the proposed emissions reductions commitments entered into for 2008-2012 by Annex 1 Parties to the UNFCCC. This places forestry alongside biofuel production as a land using activity that can, within the jurisdictions of these Parties, and possibly elsewhere through cooperation with other Parties, be encouraged to achieve the ultimate 
objective of the UNFCCC. It is obvious that such a policy assumes a large-scale intervention in the allocation of land, as well as in the energy market. This leads to questions of the costs and consequences of such a policy.

It is believed that the first attempt to model an impact of policy-specified land-use changes that deals with carbon mitigation, including biofuel production and sequestration forestry together in interacting markets was the FLAMES (fuel/forest/food land allocation model for energy/environment sustainability) model $[10,11]$. FLAMES is an equilibrium model of three interacting markets: energy, forest products and land, under large-scale land allocation for biofuel production and sequestration forestry. In this paper, we report further developments and refinements of the model.

\section{Model}

The main objective of this paper is to model the impact of large scale biofuel production on the world fuel and conventional wood products markets and to estimate the cost of a policy aimed at the reduction of carbon in the atmosphere by means of sequestration forestry and biofuel production. We study the response of three interacting marketsenergy, forest products, and land to user-specified allocations of the areas of land for biofuel production and sequestration. We abstract from the detail of markets for fuel and power, and for forest products (with "energy" standing for all fuels and other commercial energy resources and "wood" standing for pulp, roundwood chips and other conventional forest products).

The model comprises three market equations for three price variables: the consumers' price of biofuel, $P$, the price of conventional forestry product, $s$, and the rent on land, $r$.

The model assumes short term financing, with the net costs of the land allocation policy transferred, on the "polluter pays" principle, directly to energy consumers by the means of a dedicated tax on fossil carbon emitted. The dedicated carbon-tax is equivalent to the absorption obligation proposed in [9].

The prime source of the carbon emission is fossil fuels, and hence it is the subject of the carbon-dedicated tax. Biofuel is not a subject to the tax since use of these does not increase the atmospheric carbon content. That is the consumers' price of both biofuel and fossil fuel, along with the producers' price of biofuel, is $P$.

If a dedicated tax per tonne of fossil carbon emitted is $\tau$, then the consumers' price $P$ is related to the producers' price of fossil fuel $p$ via the equation

$$
P=p+\tau
$$

2.1. Land market. Following [12], we assume that all the available land $L$ is partitioned into five classes: land for conventional use (agriculture, husbandry, etc.), $L_{c}$; existing plantation land (commercial forests, i.e., commercial plantations plus natural forest allocated for timber production), $L_{p}$; land allocated for biofuel production (or "the short-rotation policy land"), $L_{\text {short }}$; land for sequestration (or "the long-rotation policy land"), $L_{\text {long }}$ and land left to wilderness $L_{\text {wild. }}$ That is

$$
L=L_{c}+L_{p}+L_{\text {short }}+L_{\text {long }}+L_{\text {wild }} .
$$


The area of the available land, $L$, represents all the land that is either currently in landbased productive use or might be so used. It excludes from the available land area permanently barren land-desert, ice and urban coverage-and most natural forests which are unlikely to be exploited for logging. We assume that the available land $L$ is either constant or slowly decreasing (due to increase of the area of urban coverage) with time $t$, for example, [12]

$$
L(t)=k_{1}-k_{2} t
$$

The land for conventional use, $L_{c}$, is a function of time $t$, and rent $r$, monotonically increasing with time and decreasing with rent. Following [12], we assume that

$$
L_{c}(t, r)=\left(k_{15}-k_{16} r\right)(1-\alpha \tau)^{k_{17}} \exp \left(k_{L} t\right) \frac{N(t)}{N_{0}} .
$$

Rent $r$ increases as the area of the land left to wilderness shrinks, that is, $\partial L_{\text {wild }} / \partial r<0$. Following [12], we assume that

$$
L_{\text {wild }}=\left(\frac{k_{13}}{r}\right)^{k_{14}}, \quad L_{p}=k_{18}-k_{19} t
$$

Here $k_{i}$ and $\alpha$ are positive parameters, $\tau$ is the carbon-dedicated tax, $N(t)$ is the global population at time $t$ and $N_{0}$ is the population at beginning of the policy.

An allocation of land for carbon sequestration and biofuel production is policy specified, that is, $L_{\text {short }}$ and $L_{\text {long }}$ are given functions of time. A way to define land allocation is to specify a planting policy, that is, to define planting programs for long- and shortrotation land.

2.2. Biofuel and wood production. The land areas $L_{p}, L_{\text {long }}$, and $L_{\text {short }}$ produce biomass $M_{p}, M_{\text {long }}$, and $M_{\text {short }}$, respectively. The land areas $L_{p}$ and $L_{\text {long }}$ are allocated to trees, while the biofuel land $L_{\text {short }}$ is used for shorter-rotation plants. If $l_{\text {long }}(t)$ and $l_{\text {short }}(t)$ are planting programs for long- and short-rotation lands $L_{\text {long }}$ and $L_{\text {short }}$, and $t_{\text {long }}$ and $t_{\text {short }}$ are the rotation periods, and $d_{\text {long }}$ and $d_{\text {short }}$ are the land productivity values, then the biomass harvested annually from these lands is proportional to the areas planted $t_{\text {long }}$ or $t_{\text {short }}$ years ago, that is

$$
\begin{aligned}
M_{\text {long }}(t) & =d_{\text {long }} l_{\text {long }}\left(t-t_{\text {long }}\right), \\
M_{\text {short }}(t) & =d_{\text {short }} l_{\text {short }}\left(t-t_{\text {short }}\right) .
\end{aligned}
$$

We assume that a constant portion ( $\operatorname{say} 1 / t_{p}$, where $t_{p}$ is the rotation period) of the existing plantations $L_{p}$ is harvested annually. Then the biomass $M_{p}$ obtained is assumed to be proportional to the harvested area, and to the land productivity $d_{p}$,

$$
M_{p}=\frac{d_{p}}{t_{p}} L_{p}
$$

Following [12], we assume that the productivity of forestry, $d_{p}$ and $d_{\text {long }}$, are constant, whereas, due to technological development the productivity of the biofuel land grows 
4 Modelling market impacts and land allocation

with time,

$$
d_{\text {short }}=d_{0}\left(1+\frac{2 t}{t^{*}}\right)
$$

where $t^{*}$ is the time horizon (here $t^{*}=70$ years).

Harvested biomass can be used to produce conventional wood product (timber), of mass $W$, and bioenergy $B$. Note that we measure biomass and wood product in units of mass (tonne), while biofuel is measured by its energy contents: one tonne of dry biomass contents $k_{M}$ units of energy $\left(k_{M} \approx 20 \mathrm{GJ} /\right.$ tonne $)$. Of course, $B_{j} / k_{M}+W_{j} \leq M_{j}$, where $j$ is $p$, long, or short.

Let

$$
\kappa_{j}=\frac{B_{j}}{k_{M} M_{j}}, \quad \sigma_{j}=\frac{W_{j}}{M_{j}},
$$

that is $\kappa_{j}$ and $\sigma_{j}$ are fractions of biofuel $B_{j}$ and timber $W_{j}$ in the biomass $M_{j}$ harvested from the land $L_{j}$. The fraction of each product depends on the products prices. Following [12], and presuming that the same technological process is applied to trees from lands $L_{p}$ and $L_{\text {long }}$, we assume that

$$
\begin{array}{ll}
\kappa_{\text {short }}=k_{35}+\left(k_{35}-1\right) \chi, & \kappa_{p}=\kappa_{\text {long }}=k_{36}+\left(k_{36}-1\right) \chi, \\
\sigma_{\text {short }}=\left(1-k_{35}\right)(1+\chi), & \sigma_{p}=\sigma_{\text {long }}=\left(1-k_{36}\right)(1+\chi),
\end{array}
$$

where

$$
\chi=\frac{2}{\pi} \arctan \left(A \frac{s-k_{M} P}{s_{0}-k_{M} P_{0}}-B\right) .
$$

Here $A=2 B=24$ and $P_{0}, s_{0}$ are initial values of $P$ and $s$, respectively. Initially $\chi \approx 1$ and, with $k_{35}=0.95$ and $k_{36}=0.625$, the product split for $M_{\text {short }}$ is $90: 10$ and for mature timber 25:75. (Note that $P$ is price of energy while $s$ is price of biomass; therefore the coefficient $k_{M}$ appears in the equations.)

2.3. Fuel and timber demand-supply balance. For an market in equilibrium supply equals demand. For the energy market, supply is a sum of nonbiofuel energy, $H$, and biofuel, $B$, that is

$$
H+B=D
$$

Here the demand for energy $D$ is a monotonically decreasing function of consumers price, $P$; the supply of nonbiofuel energy $H$ is an increasing function of producers price, $p$. The supply of the biofuel, $B$, is composed of the biofuel from the short-rotation land, the biofuel from the long-rotation land, and the commercial forests, that is

$$
B=B_{\text {long }}+B_{\text {short }}+B_{p}
$$


A. Korobeinikov et al. 5

where

$$
\begin{aligned}
B_{\text {long }}= & \kappa_{p} k_{M} M_{\text {long }}, \quad B_{p}=\kappa_{p} k_{M} M_{p}, \\
& B_{\text {short }}=\kappa_{\text {short }} k_{M} M_{\text {short }} .
\end{aligned}
$$

Following [12], we assume that demand shifts with time and is depressed by the macroeconomic impact of the dedicated tax, and has underlying constant elasticity structure,

$$
\begin{gathered}
D(P, t)=\left(\frac{k_{10}}{P}\right)^{k_{11}}(1-\alpha \tau)^{k_{12}} \exp \left(k_{B} t\right) \frac{N(t)}{N_{0}}, \\
H(p, t)=\left(k_{6}+k_{7} p\right) \exp \left(k_{8} t\right),
\end{gathered}
$$

where $k_{6}, k_{7}, k_{8}, k_{10}, k_{11}, k_{12}, k_{B}$, and $\alpha$ are positive parameters.

Fossil fuel energy, $H_{F}$, which is primarily responsible for carbon dioxide emission and is a subject to the carbon-dedicated taxes, makes a fraction of the nonbiofuel energy $H$. Following [12],

$$
H_{F}(p, t)=\left(k_{6}+k_{7} p\right) \exp \left(k_{21} t\right)
$$

where $0<k_{21}<k_{8}$ represent the decarbonisation of nonbiofuel energy due to technological progress.

For the timber market the wood product supply $W$ is a sum of the long-rotation land wood product, $W_{\text {long }}=\sigma_{p} M_{\text {long }}$, the commercial forestry product, $W_{p}=\sigma_{p} M_{p}$, and the short-rotation land wood product, $W_{\text {short }}=\sigma_{p} M_{p}$. In equilibrium, supply meets demand, that is

$$
W_{p}+W_{\text {long }}+W_{\text {short }}=D_{W}
$$

The demand for timber $D_{W}$ decreases with the product price $s$ and grows with time $t$. Following [12],

$$
D_{W}(s, t)=\left(\frac{k_{31}}{s}\right)^{k_{32}}(1-\alpha \tau)^{k_{33}} \exp \left(k_{W} t\right) \frac{N(t)}{N_{0}},
$$

where $k_{31}, k_{32}, k_{33}, k_{W}$ are positive parameters.

2.4. Policy cost. In equilibrium, the total revenue meets the cost of policy. The total revenue is composed of the revenue from the biofuel sales,

$$
U_{B}=P\left(B_{\text {long }}+B_{\text {short }}\right)
$$

the revenue from the wood product sales,

$$
U_{W}=s\left(W_{\text {long }}+W_{\text {short }}\right) \text {, }
$$

and the revenue from the tax on the carbon emitted,

$$
T=\tau H_{F}
$$


The revenue from the biofuel and the timber from the commercial plantations $L_{p}$ are not included since these accrue with existing commercial operators. The policy costs, $Q$, is a sum of the total rent, $R=r\left(L_{\text {long }}+L_{\text {short }}\right)$, the establishment costs proportional to the areas sown, $\hat{q}_{\text {short }} l_{\text {short }}(t)+\hat{q}_{\text {long }} l_{\text {long }}(t)$, annual costs of maintenance proportional to the land area, $q_{\text {short }} L_{\text {short }}+q_{\text {long }} L_{\text {long }}$, and the costs of harvesting assumed to be proportional to biomass harvested from the corresponding area, $\tilde{q}_{\text {short }} M_{\text {short }}+\tilde{q}_{\text {long }} M_{\text {long }}$. Hence, in equilibrium

$$
P\left(B_{\text {long }}+B_{\text {short }}\right)+s\left(W_{\text {long }}+W_{\text {short }}\right)+\tau H_{F}=Q,
$$

where

$$
\begin{aligned}
Q= & r\left(L_{\text {long }}+L_{\text {short }}\right)+\hat{q}_{\text {short }} l_{\text {short }}+\hat{q}_{\text {long }} l_{\text {long }} \\
& +q_{\text {short }} L_{\text {short }}+q_{\text {long }} L_{\text {long }}+\tilde{q}_{\text {short }} M_{\text {short }}+\tilde{q}_{\text {long }} M_{\text {long }}
\end{aligned}
$$

and $\hat{q}_{\text {short }}, \hat{q}_{\text {long }}, \tilde{q}_{\text {short }}, \tilde{q}_{\text {long }}, q_{\text {short }}$, and $q_{\text {long }}$ are positive constants.

The costs-revenue balance for the commercially-used lands $L_{p}$, is

$$
R_{p}+Q_{p}+\hat{Q}_{p}+\widetilde{Q}_{p}=P B_{p}+s W_{p}
$$

It is not included in the model.

2.5. The dynamic model. To introduce dynamics into the model we assume, following Morishima [7], that the product prices rise in response to excess demand in a market. We have a system of three markets in interaction: the energy market, the timber market and the land market. Thus, we obtain an equation

$$
a_{p} \frac{d P}{d t}=D-H-B
$$

for the energy market, an equation

$$
a_{s} \frac{d s}{d t}=D_{W}-W
$$

for the timber market, and an equation

$$
a_{r} \frac{d r}{d t}=L_{p}+L_{\text {short }}+L_{\text {long }}+L_{\text {wild }}+L_{c}-L
$$

for the land market. Here $a_{p}, a_{s}, a_{b}$ are positive constants which are proportional to the corresponding time-scale and inversely proportional to the speeds of response.

Similarly, we assume that the carbon tax $\tau$ rises if "demand" — the policy cost—exceeds "supply"-the revenue from biofuel and timber sales and the tax revenue,

$$
a_{\tau} \frac{d \tau}{d t}=Q-P\left(B_{\text {long }}+B_{\text {short }}\right)-s\left(W_{\text {long }}+W_{\text {short }}\right)-\tau H_{F}
$$

Here $a_{\tau}$ are positive constants which are proportional to the corresponding time-scale and inversely proportional to the speeds of response. 
The system (2.25)-(2.28) should be solved simultaneously with the atmospheric carbon balance equation. The total atmospheric carbon, $C$, increases with burning of the fuel supplied, and decreases due to absorption of the carbon by ocean and terrestrial ecosystem, the short-rotation land, the long-rotation land, and the old plantations. We assume that emission of the carbon due to biofuel use from the short-rotation land equals absorption of the atmospheric carbon for biofuel growth. Then

$$
\frac{d C}{d t}=\beta_{H} H_{F}+\beta_{B}\left(B_{\text {long }}+B_{p}\right)-\beta_{W} W_{\text {short }}-\beta_{p}\left(L_{p}+L_{\text {long }}\right)-O_{\text {ocean }},
$$

where $\beta_{H}, \beta_{B}$, and $\beta_{W}$ are the carbon content of the fossil fuel, the biofuel and the wood product respectively; $\beta_{p}=\beta_{\text {long }}$ is the rate of the atmospheric carbon absorption by longrotation and old plantation land; $O_{\text {ocean }}$ is the rate of atmospheric carbon absorption by the ocean. We assume [12] that

$$
O_{\text {ocean }}=\beta_{O}\left(C-C_{\mathrm{cr}}\right) \text {, }
$$

where $\beta_{O}$ is the first-order rate coefficient of carbon absorption by the ocean, with $C_{\mathrm{cr}}=$ 560 .

\section{Results}

Following [10-12], let as consider market responses under three scenarios:

(a) no policy;

(b) allocation of land for biofuel production only;

(c) allocation of land for biofuel production and for sequestration forestry.

Under the third scenario, sequestration is not treated as permanent, as in previous studies (e.g., [6]), but as a several decades low cost "buffer stock" of carbon, to be utilised as wood and biofuel at a time when demand for this raw material has developed. This keeps open the precautionary option of 100 per cent use of this stock as biofuel in the event science reveals a low threshold for adverse climate surprises $[1,13]$.

Land allocations for these three scenarios are given by Figure 3.1.

We will assume that the policy is applied for 70 years, so that a time horizon of 70 years has been used in all work to date. This period broadly represents twice the rotation period for forestry, as well as twice the turnover period for the long-lived energy sector capital stock. The former is convenient for modelling but the latter is more significant because the energy-sector technological inertia is related to heavy sunk costs with the main obstacle to a rapidly effective response strategy that stabilises, or reduces current greenhouse gas levels through change in the energy sector alone.

The 70-years time horizon is preferred to the 100-years time horizon used by some analysts [5] because a longer horizon, with three generations of capital re-equipment, enables technological change in developed countries to be delayed [2], in such a manner that fails to provide the lead-time expected by developing countries. 
8 Modelling market impacts and land allocation

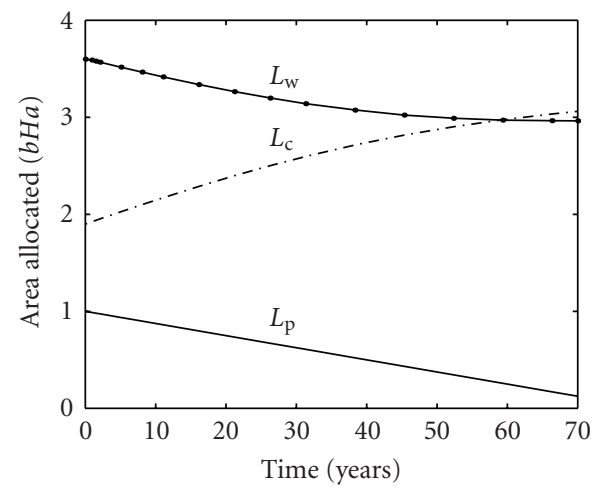

(a)

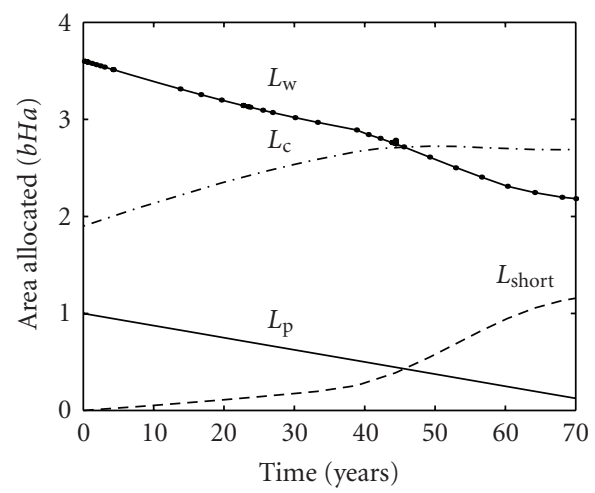

(b)

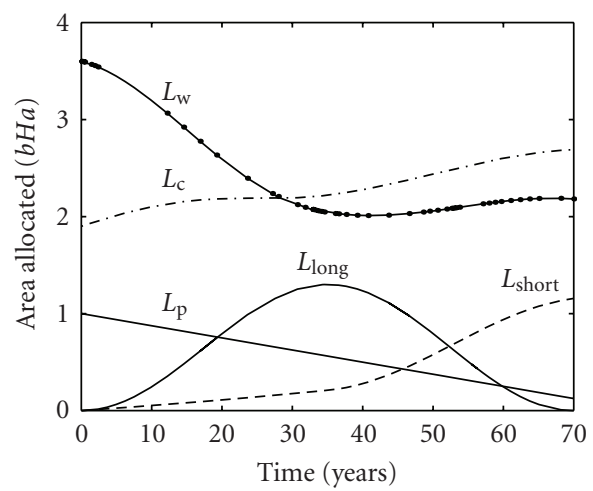

(c)

Figure 3.1. Land allocation for the three scenarios: (a) no policy land, (b) allocation of land for biofuel, and (c) allocation of land for biofuel and sequestration forestry. 
A. Korobeinikov et al. 9

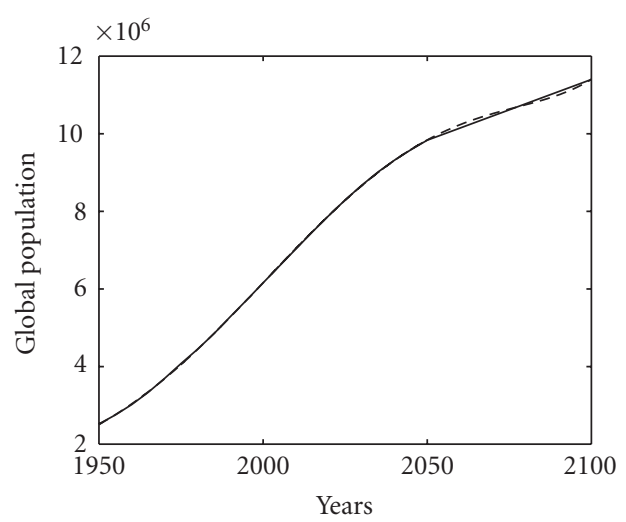

Figure 3.2. Global population forecast: the United Nations official forecast (solid line) and its approximation by the polynomial (3.1) (broken line).

The global population $N(t)$ is approximated by a fifth order polynomial

$$
N(t)=\sum_{j=1}^{6} c_{j} t^{6-j},
$$

where $c_{1}=4.1067 \times 10^{-4}, c_{2}=-2.1186 \times 10^{-1}, c_{3}=3.6331 \times 10^{1}, c_{4}=-2.2723 \times 10^{3}$, $c_{5}=9.5760 \times 10^{4}$, and $c_{6}=5.4219 \times 10^{4}$, which fits with good accuracy the United Nations official population dynamics forecast (medium variant) on the time interval from 1950 to 2050 [16] and United Nations population estimates for 2050 to 2100 (see Figure 3.2).

Figure 3.3 represent the corresponding market responses for the three scenarios. The change of atmospheric carbon contents for the scenario is given by Figure 3.4. As demonstrated by Figure 3.4, allocating large areas of land to two activities-a long-term buffer stock of carbon sequestrated from the atmosphere and short-rotation biofuel production-has a very substantial beneficial impact on the timing and quantum of greenhouse gas level reductions. With both biofuel production and buffer stock sequestration comparatively low, carbon-dedicated tax is required for up to 35 years to meet the cost of creating the buffer stock. After 35 years the dedicated tax is zero and the policy actually brings a profit. After 35 years, energy prices are also reduced on account of additional biofuel supply from the desequestration process. The results indicate that an integrated forestry-based strategy, in which land in first used for buffer stock sequestration and subsequently converted to biofuel production may offer the prospect of controlling greenhouse gases levels more effectively and at lower cost than has previously been shown to be practical $[10,11]$.

\section{Conclusion}

An objective of this work was to substantiate the view advanced in [9] and corroborated by others [4], that a land allocation policy with the aim of biofuel production and sequestration forestry can play a major role in controlling carbon dioxide levels. Another 
10 Modelling market impacts and land allocation
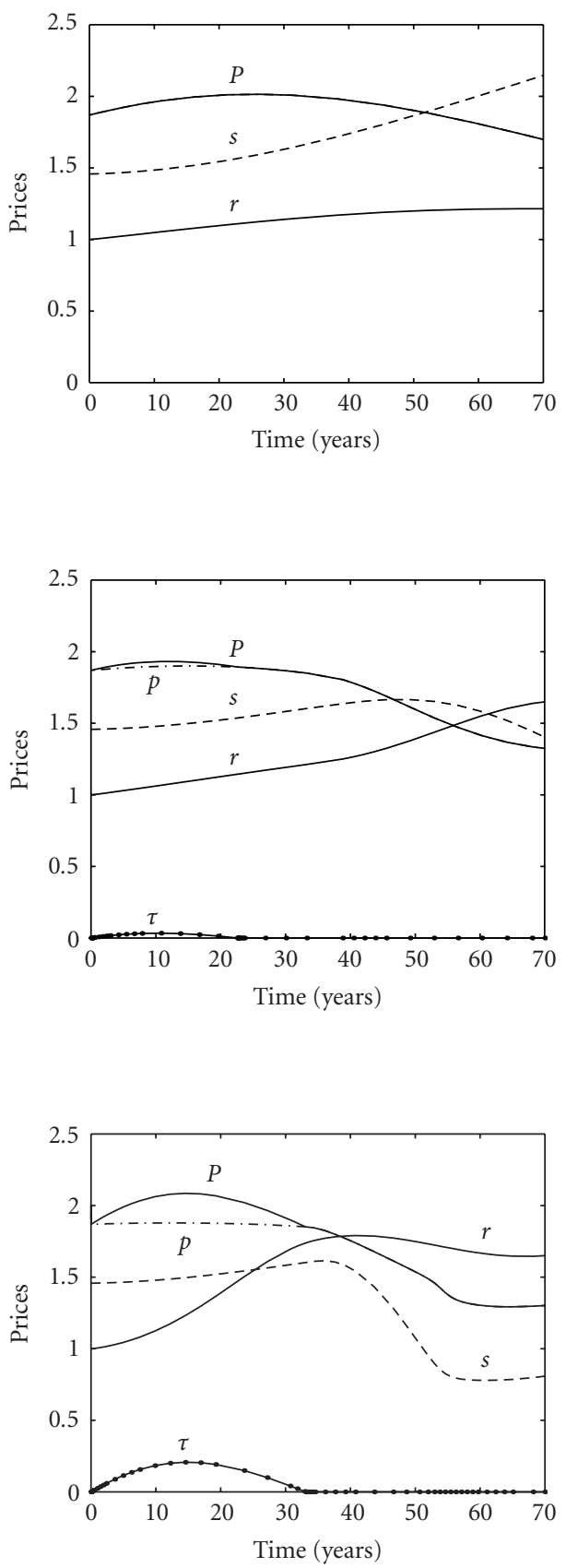

Figure 3.3. The consumers' and producers' prices of energy and tax $(\$ / G J)$, rent $(10 \times \$ / \mathrm{Ha})$ and price of wood products $(100 \times \$ / t)$ for the three scenarios, respectively. 


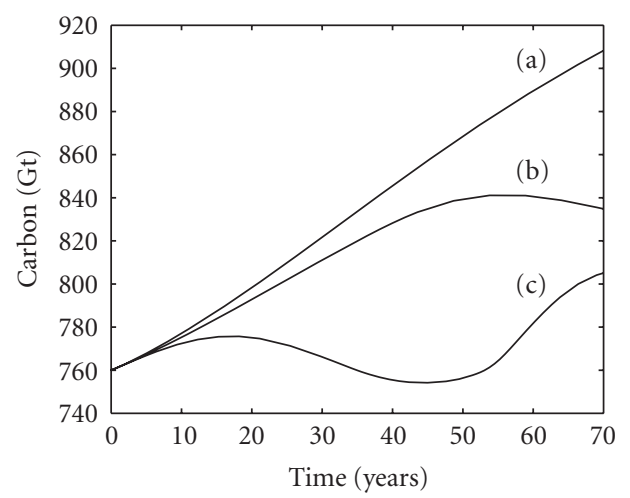

Figure 3.4. Atmospheric carbon contents for the three scenarios.

objective was to investigate the market impacts of such land allocation policies with a view to quantifying these effects, identifying gains and losses and suggesting policy options that can lead market outcomes towards the least cost for safe levels of carbon dioxide concentrations in the atmosphere.

In relation to the first objective, it is shown that if sufficient land is used, the impact on carbon dioxide levels of policy driven land allocations is such as has not been regarded as practicable under alternative policies $[3,14,15]$. The model demonstrated, on a global basis, that large scale allocation of land to the growing of trees, either on long rotation, for traditional forest products or on short rotation for biofuel, can achieve low cost reductions in carbon dioxide levels that are otherwise not feasible.

Despite the obvious relevance of these results to policy, they are not sufficient to be applied to policy issues since the model is global while policy is determined at national levels. A subsequent paper outlines the development of a multi-regional model with interregional trade flows that capable of establishing world prices for fossil fuel, biofuel and woody raw materials. The world prices would enable models for individual countries to be developed, and establish whether the country will export or import these products.

Given the geo-political aspects of policy, a model which treats the globe as a whole can provide little insight. This aspect is reinforced by the fact that UNFCCC Annex 1 countries are mainly located in higher latitudes with temperate climates and moderate to poor growing conditions. Together with oil producing countries, they have greater sunk costs in the energy sector and lower growth prospects than developing economies. Thus a regionalized model that reflects these broad differences is needed before the market impacts can be modelled satisfactorily. Such a model, distinguishing a low energy cost, low photosynthetic productivity, high income and reducing growth region from a contrasting developing region, is a research priority.

\section{References}

[1] N. Greene, F. E. Celik, B. Dale, M. Jackson, K. Jayawardhana, H. Jin, E. D. Larson, M. Laser, L. Lynd, D. MacKenzie, J. Mark, J. McBride, S. McLaughlin, and D. Saccardi, Growing Energy. How 
12 Modelling market impacts and land allocation

Biofuels Can Help End America's Oil Dependence, Natural Resources Defense Council, New York, 2004.

[2] M. Grubb, The Berlin Climate Conference: Outcome and Implications, Briefing Paper no. 21, RIIA, Chatham House, London, 1995.

[3] , Technologies, energy systems and the timing of $\mathrm{CO}_{2}$ emissions abatement, Energy Policy 25 (1997), no. 2, 159-172.

[4] G. H. Kohlmaier, R. A. Houghton, and M. Weber (eds.), Carbon Dioxide Mitigation in Forestry and Wood Industry, Springer, Berlin, 1997.

[5] A. S. Manne and R. G. Richels, Buying Greenhouse Insurance: The Economic Costs of Carbon Dioxide Emission Limits, MIT Press, Massachusetts, 1992.

[6] G. Marland, The prospect of solving the $\mathrm{CO}_{2}$ problem through global reforestation, Tech. Rep. DOE/NBB-0082, National Technical Information Service, Virginia, 1988.

[7] M. Morishima, A reconsideration of the Walras-Cassel-Leontief model of general equilibrium, Mathematical Methods in the Social Sciences, 1959 (K. J. Arrow, S. Karlin, and P. Suppes, eds.), Stanford University Press, California, 1960, pp. 63-76.

[8] P. Read, The political economy of a biomass energy response to global warming, International Journal of Global Energy Issues 4 (1992), no. 4, 275.

[9] _ Responding to Global Warming: The Technology, Economics and Politics of Sustainable Energy, Zed Books, London, 1994.

[10] _ Food, fuel, fibre and faces to feed. Simulation studies of land use change for sustainable development in the 21st century, Ecological Economics 23 (1997), no. 2, 81-93.

[11] Dynamic interaction of short rotations and conventional forestry in meeting demand for bioenergy in the least cost mitigation strategy, Biomass and Bioenergy 15 (1998), no. 1, 7-15.

[12] _ The Role of Biomass in Meeting Greenhouse Gas Reduction Targets: Land Allocation Modeling of Key Market Impacts, Massey University, Palmerston North, 1999.

[13] P. Read and J. Lermit, Bio-energy with carbon storage (BECS): a sequential decision approach to the threat of abrupt climate change, Energy 30 (2005), no. 14, 2654-2671.

[14] S. H. Schneider and L. H. Goulder, Achieving low-cost emissions targets, Nature 389 (1997), no. 6646, 13-14.

[15] R. T. Watson (ed.), Climate Change 2001: Synthesis Report. Contribution of Working Groups I, II, and III to the Third Assessment Report of the Intergovernmental Panel on Climate Change, Cambridge University Press, Cambridge, 2001.

[16] World Population 1950-2050 (Medium Variant), Population Division of the Department of Economic and Social Affairs of the United Nations Secretariat, World Population Prospects: The 2004 Revision and World Urbanization Prospects: The 2003 Revision, 2004 http://esa.un.org/unpp.

A. Korobeinikov: Research Institute for Electronic Sciences, Hokkaido University, Sapporo 060-0821, Japan

P. Read: Department of Applied and International Economics, Massey University, Palmerston North, New Zealand

A. Parshotam: Department of Mathematics, Institute of Fundamental Sciences, Massey University, Palmerston North, New Zealand

E-mail address: a.parshotam@massey.ac.nz

J. Lermit: Energy Consultant, 2/109 Hill Street, Thorndon, Wellington, New Zealand 


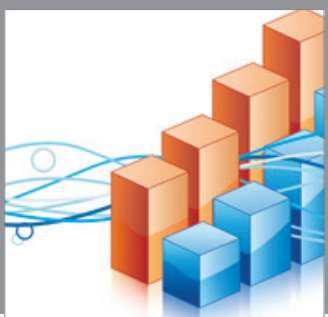

Advances in

Operations Research

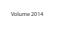

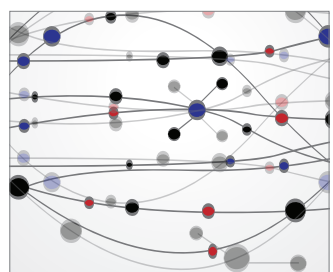

\section{The Scientific} World Journal
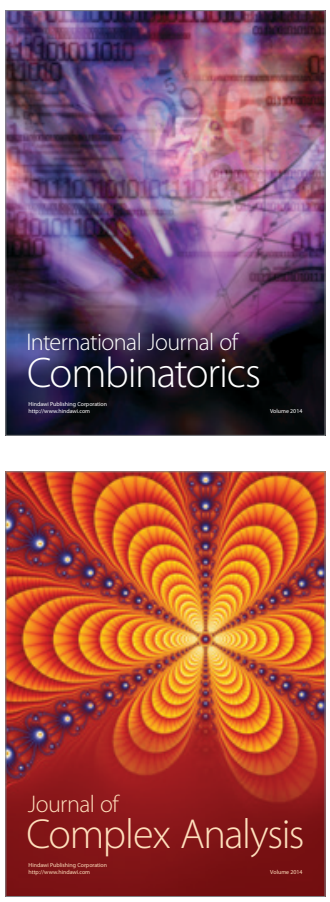

International Journal of

Mathematics and

Mathematical

Sciences
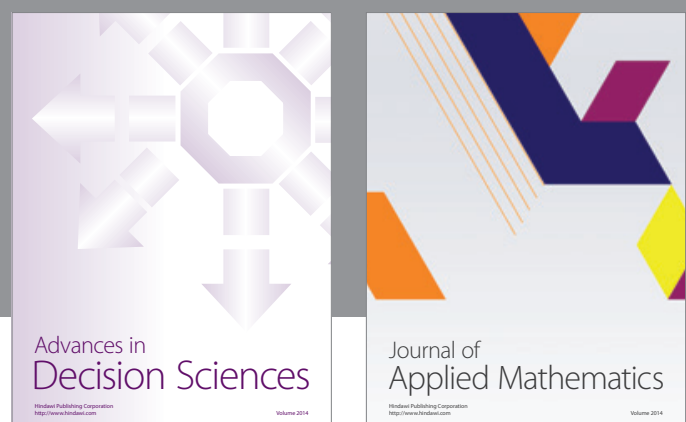

Journal of

Applied Mathematics
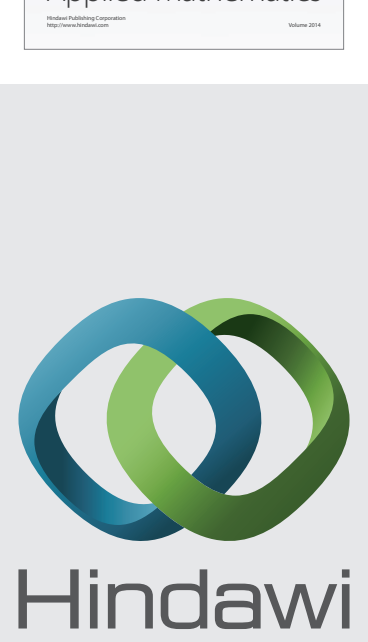

Submit your manuscripts at http://www.hindawi.com
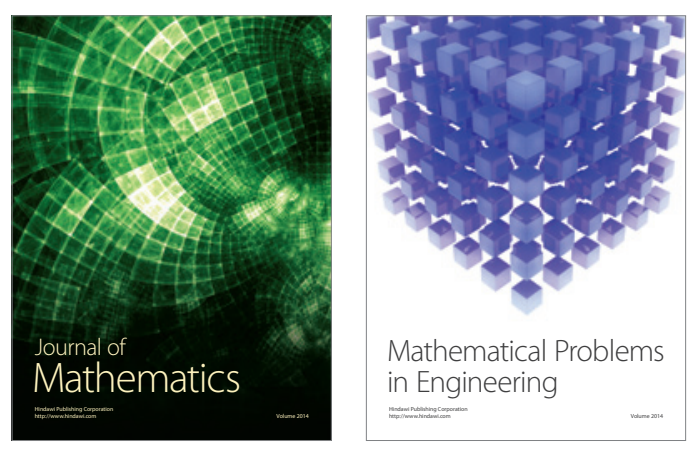

Mathematical Problems in Engineering
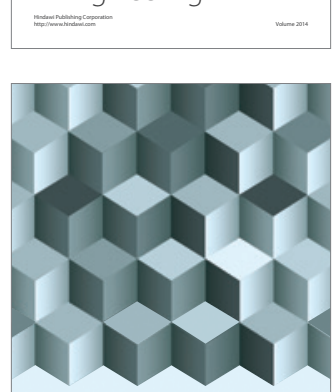

Journal of

Function Spaces
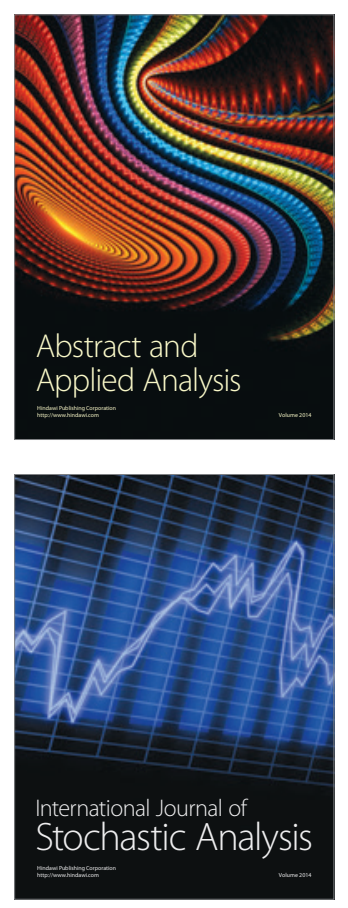

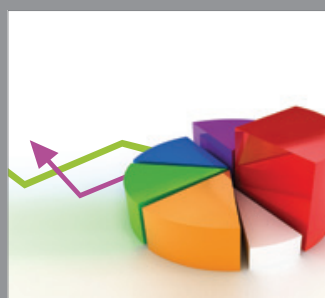

ournal of

Probability and Statistics

Promensencen
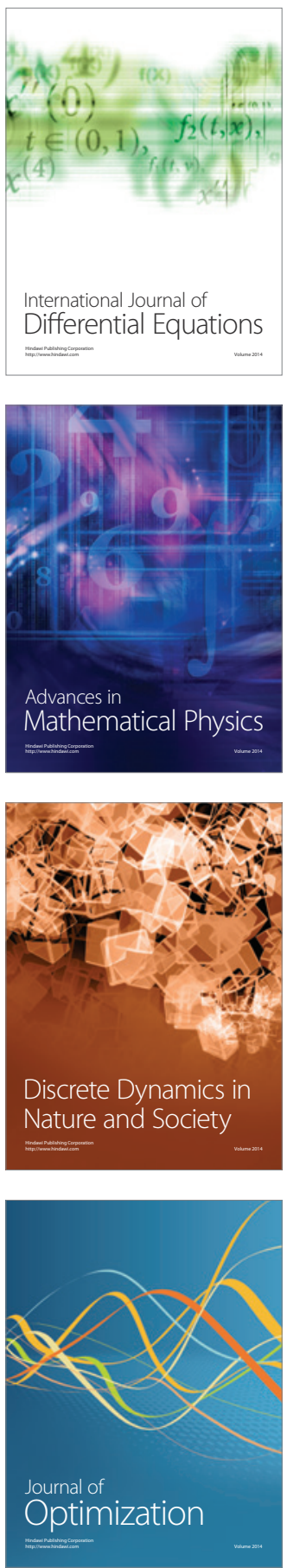